\title{
Cerebellar Dysfunction of Movement and Perception
}

\author{
H.C. Diener, J. Hore, R. Ivry and J. Dichgans
}

\begin{abstract}
This review describes some characteristics of patients with cerebellar lesions, including limb movements, changes in motor planning and disturbances in time-dependent perception. The delay in movement initiation can be explained by a delay in onset of movement-related discharge of neurons in motor cortex. Disorders of movement termination (hypermetria) are accompanied by asymmetric velocity profiles and by prolonged agonist and delayed antagonist EMG activity necessary to brake the movement. During complex movements in three-dimensional space, the cerebellum contributes to timing between single components of a movement, scales the size of muscular action, and coordinates the sequence of agonists and antagonists. The basic structure of motor programs is not generated exclusively within the cerebellum and patients with cerebellar lesions can use precuing information to improve their motor performance. Time-dependent perception in the auditory and visual domains are disturbed in patients with cerebellar lesions.
\end{abstract}

RÉSUMÉ: Dysfonction cérébelleuse du mouvement et de la perception. Cette revue décrit certaines caractéristiques de patients atteints de lésions cérébelleuses, particulièrement en ce qui a trait aux mouvements des membres, aux changements dans la planification motrice et aux perturbations de la perception temporelle. Le délai dans l'initiation du mouvement peut être expliqué par un délai dans le début de la décharge, reliée au mouvement, des neurones moteurs corticaux. Les désordres de la fin du mouvement (hypermétrie) sont accompagnés par des profils de vélocité asymétriques, ainsi qu'une prolongation de l'activité agoniste et un délai de l'activité antagoniste EMG nécessaires pour freiner le mouvement. Pendant les mouvements complexes dans un espace tri-dimensionnel, le cervelet contribue à la synchronisation entre chacune des composantes d'un mouvement, ajuste l'amplitude de l'action musculaire et coordonne la séquence de l'action des agonistes et des antagonistes. La structure de base des programmes moteurs n'est généralement pas exclusivement localisée dans le cervelet et les patients qui ont des lésions cérébelleuses peuvent utiliser des éléments de programmes déjà connus comme indices pour améliorer leur performance motrice. La perception temporelle dans les domaines auditifs et visuels est perturbée chez les patients ayant une lésion cérébelleuse.

Can. J. Neurol. Sci. 1993; 20 (Suppl. 3): S62-S69

Disorders of the cerebellum result in clinical signs and symptoms that were comprehensively described and summarized by Holmes in $1917,^{1} 1922^{2-5}$ and $1939^{6}$ and later by Dow and Moruzzi ${ }^{7}$ as well as Gilman et al. ${ }^{8}$ Lesions of the lateral parts of the posterior cerebellar hemisphere cause dyssynergia, dysmetria, dysdiadochokinesia, and dysarthria. Damage to the cerebellar vermis and the anterior lobe results in ataxia of stance and gait. Lesions of flocculus and paraflocculus result in an inability to stabilize a visual target on the retina. The cerebellum therefore, despite its homogeneous structure may be subdivided into functional compartments, and specific motor functions can be ascribed to these subunits. ${ }^{8-11}$ Despite considerable knowledge from animal and human physiology and pathophysiology, ${ }^{9.11}$ we still lack a widely-accepted hypothesis of the principal way in which the uniform anatomical structure of the intrinsic cerebellar network contributes to the control of movement.

This review 1) will describe the features of pathological versus normal limb movements in cerebellar disorders, 2) will dis- cuss the changes in motor planning in patients with cerebellar lesions and 3) will report disturbances in time-dependent perception with cerebellar dysfunction.

\section{Pathophysiology of Cerebellak Disorders OF Limb MOVEMENTS}

\section{Delay of Movement Initiation}

The delay in the initiation of a movement has been observed both in humans with cerebellar disorders and animals with cerebellar lesions. ${ }^{1,12-18}$ The delay in movement onset can be seen in proximal and distal joints, e.g., in fast elbow, wrist and finger movements ${ }^{19}$ (Figure 1) as well as in slow visuo-motor tracking tasks. ${ }^{20}$ Lesions of the dentate nucleus (the output relay of the cerebellar hemispheres) in monkeys resulted in increased reaction times (RT) when triggered by visual and auditory stimuli..1 Increased RT were seen after cooling of the dentate nucleus irrespective of whether simple or complex movements were

From the Department of Neurology, University of Essen, FRG (HCD), the Department of Physiology, University of Western Ontario, London, Canada $(\mathrm{JH})$, the Department of Psychology, University of California, Berkeley, USA (RI) and the Department of Neurology, University of Tübingen, FRG (JD)

Reprint requests to: H.C. Diener, M.D., Neurologische Universitätsklinik, Hufelandstr. 55 , D4300 Essen, FRG 
performed. ${ }^{17}$ This result suggests that the cortico-ponto-neocerebellar loop, with its efferents through dentate and thalamus back to the motor cortex, takes part in the initiation of fast movements. In accordance with this hypothesis, it has been observed that neurons in the neocerebellar cortex and dentate nucleus change their discharge frequency prior to activation of motor cortical neurons ${ }^{22}$ and that movement-related responses of cortical neurons are delayed when there is dentate dysfunction. ${ }^{13.23-24}$

\section{Dysmetria and Dyskinesia}

According to our clinical observations, hypermetria can most often be observed in fast movements, while hypometria occurs with slow movements of small amplitude. In a recent series of experiments we studied fast, goal-directed movements at the elbow, wrist and finger in a reaction time paradigm in which subjects moved a manipulandum..$^{18}$ Cerebellar patients almost always showed an excessive extent of movement (hypermetria). This was seen in all three joints investigated. Hypermetria was most marked for aimed movements of small $\left(5^{\circ}\right)$ amplitudes.

For each of six patients, movements performed with all three joints over all three amplitudes $\left(5,30,60^{\circ}\right)$ were characterized to various degrees by an asymmetry with decreased peak accelerations and increased peak decelerations compared to normal movements. ${ }^{18}$ Similar results were found by Hallett et al. who described a prolonged acceleration time in simple rapid elbow flexions in patients with cerebellar deficits. ${ }^{25}$ Elbow flexions in monkeys performed during reversible cooling of the cerebellar nuclei, when compared with control movements of the same peak velocity, also showed smaller magnitudes of acceleration and larger magnitudes of deceleration. ${ }^{26}$ The uniformity of these results indicates that this asymmetry is a fundamental cerebellar sign. It has been suggested that asymmetry, and the hypermetria for small amplitude movements, could be used clinically as sensitive indicators of cerebellar dysfunction. ${ }^{18}$

The opposite asymmetry of movement parameters in cerebellar patients has been reported by others ${ }^{27}$ with movements characterized by short accelerations and long decelerations. Results

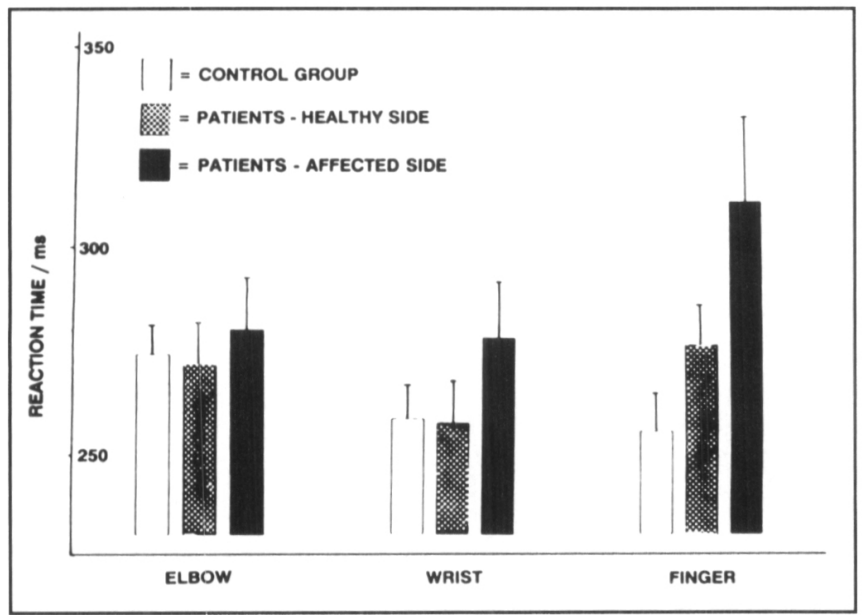

Figure I - Reaction times (means and standard deviations) of fast goal-directed movements at the elbow, wrist and index finger with an amplitude of $60^{\circ}$. Mean values were obtained from 10 normal subjects and 9 patients with unilateral cerebellar lesions. The latency differences between the normal and the affected side in patients were significant $(p<0.05)$ for all joints $\left(\right.$ from $\left.{ }^{19}\right)$. of the two studies cannot easily be compared because the patients from the second study ${ }^{27}$ had mild cerebellar impairments and the asymmetry was seen for slow but not fast movements.

What are the EMG and motor cortex discharge abnormalities that cause the disorder? Fast movements of the arm are performed with a triphasic EMG pattern. ${ }^{28}$ Normally, the first change observed is an inhibition of tonic antagonistic activity. The movement starts with a large initial burst of activity in the agonist. This burst is followed by a silent period and then a second burst of agonist activity. In the antagonist, there is a single burst which occurs at about the time of the agonist silent period and acts to brake the movement. This pattern appears to be centrally preprogrammed, in part by motor cortex, but can be influenced by peripheral feedback.

The disorder in acceleration in hypermetric movements was associated with agonist EMG activity that was less abrupt in onset, smaller in magnitude, and more prolonged in duration in both patients ${ }^{18}$ and monkeys. ${ }^{24}$ In monkeys this was associated with a decrease in phasic discharge of some agonist-related motor cortex neurons. ${ }^{23.24}$ The disorder in deceleration was associated with delayed onset of phasic antagonist EMG activity (Figure 2). ${ }^{18}$ This was also true for monkeys with cooling of the dentate nucleus who showed corresponding delays in discharge of some antagonist-related motor cortex neurons. ${ }^{24.26} \mathrm{~A}$ delay in antagonistic activity within the three-burst pattern of human elbow and thumb movements was also observed in humans by Marsden et al. ${ }^{12}$ and by Hallett and coworkers. ${ }^{25}$

Studies of the sequential activation of agonists and antagonists involved in a multijoint movement, ${ }^{29}$ and of its coordination with postural stabilization, point out, that little is yet known of the role the cerebellum plays in such complex tasks.

\section{Dysdiadochokinesia}

Diadochokinesia is tested by rapidly patting with one hand, alternating between palm up and palm down. ${ }^{30.31}$ Dysdiadochokinesia theoretically could be explained by the mechanisms described so far. Slowness at the turning points could be due to delays in movement initiation and/or dysmetria at the end of the movement. Abnormalities of movement velocity and acceleration could also contribute. In a recent experiment we investigated rapid alternating movements at the elbow, wrist and finger in cerebellar patients. Movements were slower, and irregular in amplitude and frequency on the affected side. In agreement with Conrad and Brooks ${ }^{32}$ EMG-activity on the affected side was prolonged, irregular and continued in time beyond the start of movement at the turning points (Figures 3 and 4, unpublished observation).

\section{Dysynergia}

With the new techniques for recording two- and three-dimensional movements Becker et al. ${ }^{29}$ studied throwing movements in normals and cerebellar patients. Elbow-wrist coordination and the coordination of hand opening with activation of more proximal arm muscles were preserved in patients. Patients, however, were unable to coordinate the muscles so as to produce the same hand direction from trial to trial.

In a recent experiment we investigated postural adjustments associated with the task of rising on tip-toes in a reaction time paradigm in 10 normal subjects and 18 patients with cerebellar disorders. ${ }^{33}$ The task, accomplished by the triceps surae muscle 
is mechanically effective only if the center of gravity has been shifted forward in advance. To achieve this, a phasic burst of preparatory EMG-activity in tibialis anterior normally occurs at a mean latency of $163 \mathrm{~ms}$, shifting the center of gravity forward. Shortly thereafter, activity of quadriceps femoris $(175 \mathrm{~ms})$ extends the knee and aids the forward shift of the center of gravity. Following these postural adjustments, triceps surae (executional activity, latency $411 \mathrm{~ms}$ ) raises the body on tip-toes. Different aspects of this motor sequence were disturbed in individual patients: latencies of preparatory and executional activity were uncorrelated in 15 of the 18 patients. Executional $(n=16)$ or preparatory $(n=13)$ EMG-activity was tonic instead of pha- sic (Figure 5). This resulted in a prolongation in recruitment of force. Latencies of either preparatory or executional EMG activities or both were prolonged $(n=10)$ (Figure 5). The time interval between motor preparation and execution was increased $(n=9)$. Trial-to-trial variability of biomechanical parameters and EMGlatency was also increased. Preparatory EMG-activity in quadriceps was entirely missing $(n=9)$, resulting in knee bending in the unsuccessful attempts to rise on tip-toes. Patients who were most severely affected had no preparatory activity at all $(n=2)$, and therefore were unable to perform the task. The individual pattern of disordered coordination was rather reproducible across single trials, whereas the interindividual variation was
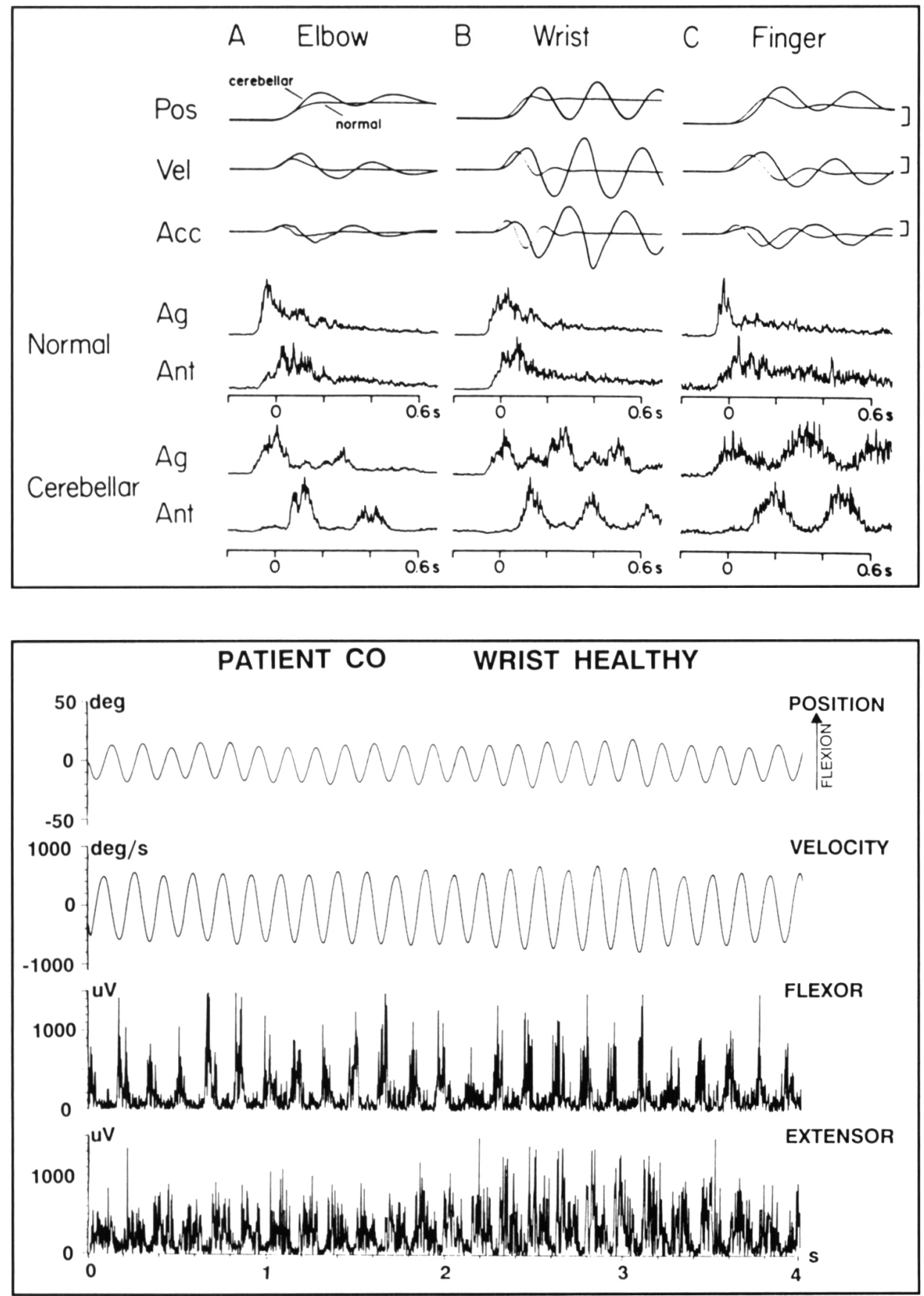

Figure 2 - Delayed antagonist EMG activity associated with hypermetria. Average records of 15-20 flexions of the normal side and on the cerebellar affected side made about the elbow $(A)$, wrist $(B)$ and finger $(C)$. Records synchronized to start of movenent time $(0$ ms). EMG records from the 2 sides were scaled to give approximately the same magnitudes. Target distance $30^{\circ}$. Calibrations: position $30^{\circ}$, velocity $300^{\circ} / \mathrm{sec}$., acceleration $2.000 \mathrm{deg} / \mathrm{s}^{2}$ $\left(\right.$ from $\left.{ }^{18}\right)$.
Figure $3-$ Rapid alternating movements of the wrist between two targets $30^{\circ}$ apart performed with the healthy side in a patient with unilateral cerebellar damage. Note the close temporal relationship between EMG onset and peaks in wrist position. 


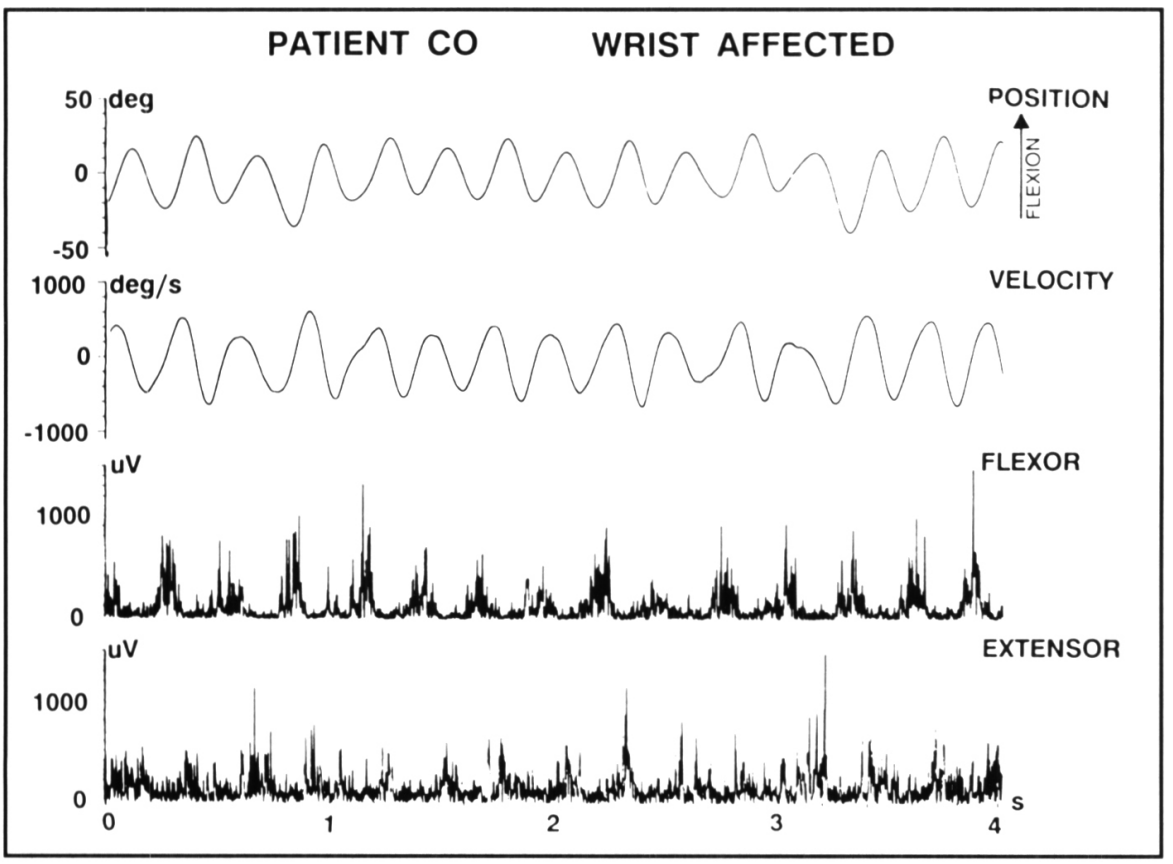

Figure 4-Rapid alternating wrist movements recorded from the affected side of the same patien (Figure 3). Note the slowing and the irregularity of the movement and the loss of temporal relationship between EMG onset and turning points of the movement.

large. These experiments demonstrate that the cerebellum contributes to the scaling of size and duration of both preparatory and executional motor activity and controls their temporal relationships.

\section{Disturbances of Motor Programming}

Fast complex movements are supposed to be preprogrammed prior to execution. The concept of a motor program ${ }^{34}$ originally derived from the observation that well-trained fast actions are executed too fast to depend on sensory feedback. This assumption may only partially be true since most movements take longer than $100 \mathrm{~ms}$ and allow spinal and transcortical feedback to contribute. It is, however, still supposed that a neural representation of an entire complex action is prepared before response onset. The action is then executed as a single unit when triggered. One of our basic hypotheses is that the cerebellum helps to coordinate the timing between the single components of a movement but is not the only constituent of a program. The basic structure of a motor program (e.g., muscle groups involved, sequence of muscles activated) is not generated exclusively within the cerebellum. Cerebellar patients are still able to perform complex motor tasks,,$^{12.20 .29}$ although the execution is slow and ataxic.

Motor programming was investigated in an experiment by Inhoff et al. ${ }^{35}$ Normal subjects and 22 patients with various cerebellar disorders were instructed to execute sequences of finger movements in a simple reaction time paradigm. Evidence for anticipatory motor programming in normal subjects was reflected in the pattern of onset times and inter-key-press times. Normal subjects and patients with mild cerebellar dysfunction showed increases in response onset time as the sequence length increased from a single to two or three consecutive finger movements. Patients with severe cerebellar symptoms showed abnormally long reaction times and no further increase in their initial reaction time with the number of finger movements to be per- formed. Furthermore, cerebellar dysfunction was associated with slower inter-key-press reaction times. This result indicates that anticipatory motor programming critically depends on cerebellar integrity.

In still unpublished experiments performed together with $\mathrm{G}$. Stelmach and F. Horak, we used the movement precuing technique to isolate the mechanisms that are involved in the preparation and execution of a voluntary movement. With this technique, a subject is provided with partial or complete information about the characteristics of an upcoming movement in a reaction-time paradigm. In a typical experiment, the subject performs a goal-directed limb movement as rapidly as possible after a reaction signal. At the start of the trial, prior to the reaction signal, the subject receives a precue about the extent and/or direction of an upcoming movement to be performed later, thus permitting preparation. The greater the number of movement parameters known in advance, the shorter the reaction and movement times. ${ }^{36.37}$

In our experiment, 14 normal subjects, 5 patients with diffuse cerebellar atrophy and 3 patients with a unilateral cerebellar lesion were asked to perform rapid reaching movements of the arm with an electromagnetic stylus on a digitizing tablet. Movements were made from a starting point in front of the subject to one of four target zones (Figure 6). The precuing information contained either the exact location of the forthcoming target (e.g., left, distant), the direction of the movement (right or left), the distance (near, distant) or no specific information. The reaction times of the cerebellar patients were increased compared to normals, but the decrease of reaction times with increasing information content of the precuing information was seen both in normals (Figure 6A) and patients with cerebellar lesions (Figure 6B, C, unpublished observations). These results show, that cerebellar patients are able to use prior information to improve their disturbed motor performance. 


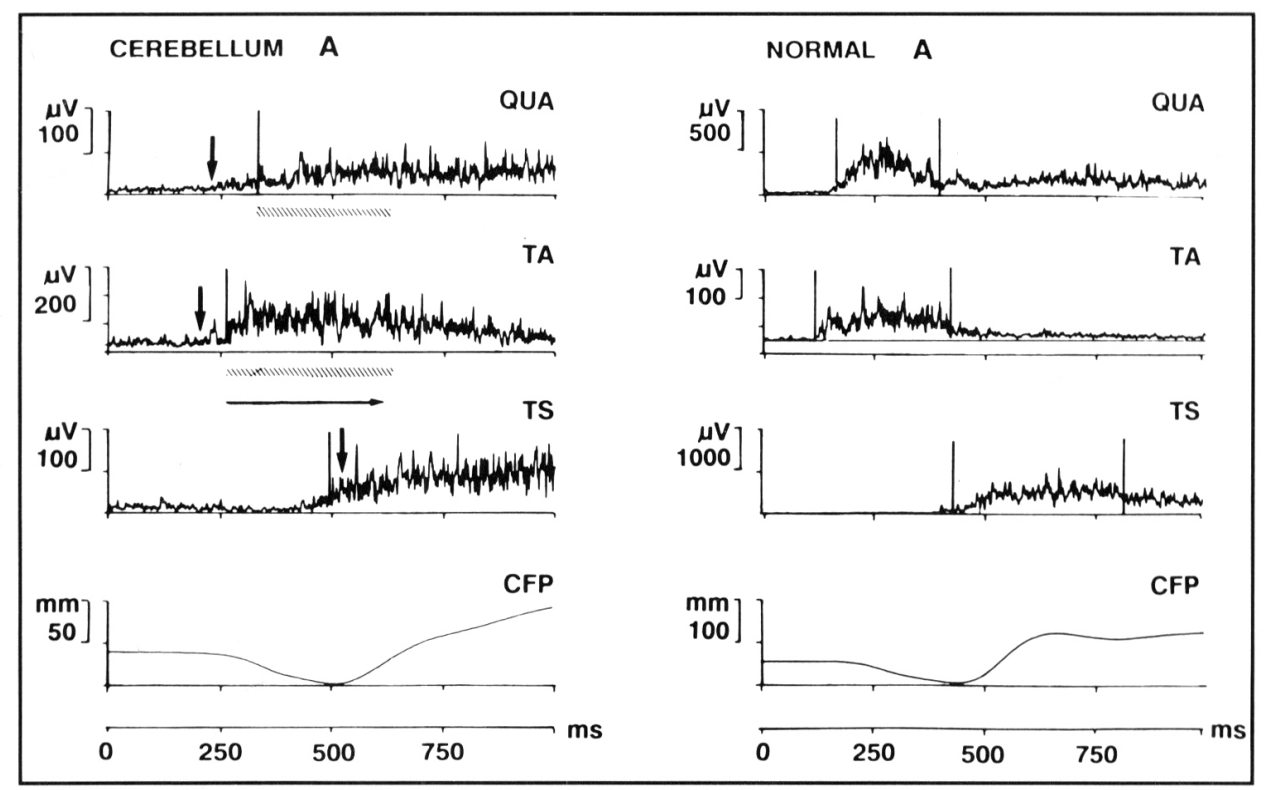

Figure 5-Coordination of posture and movement in the task to rise on tip-toes. Motor preparation is performed by phasic activity in quadriceps femoris (QUA) and tibialis anterior (TA) and the execution with triceps surae (TS). Rectified and averaged EMGs (eight runs) in a patient with cerebellar disorder on the left and an age matched normal subject on the right. The upper limit of EMG onset latency in normal subjects is shown by a big vertical arrow. The vertical lines indicate the average onset and offset latency as calculated from single trials. The longest duration of QUA and TA observed in a normal subject is indicated by the hatched bar. The horizontal arrow shows the longest time interval between TA and TS found in normals. The lowest trace depicts the displacement of the center of foot pressure (CFP). The forward shift of the body is reflected by a downward deflection of the recording of the center of foot pressure $(C F P)$, the lift to the toes by an upward deflection. Note the delay of preparatory activity in tibialis anterior and quadriceps and the tonic nature of this part of the motor pattern (from ${ }^{33}$ ).

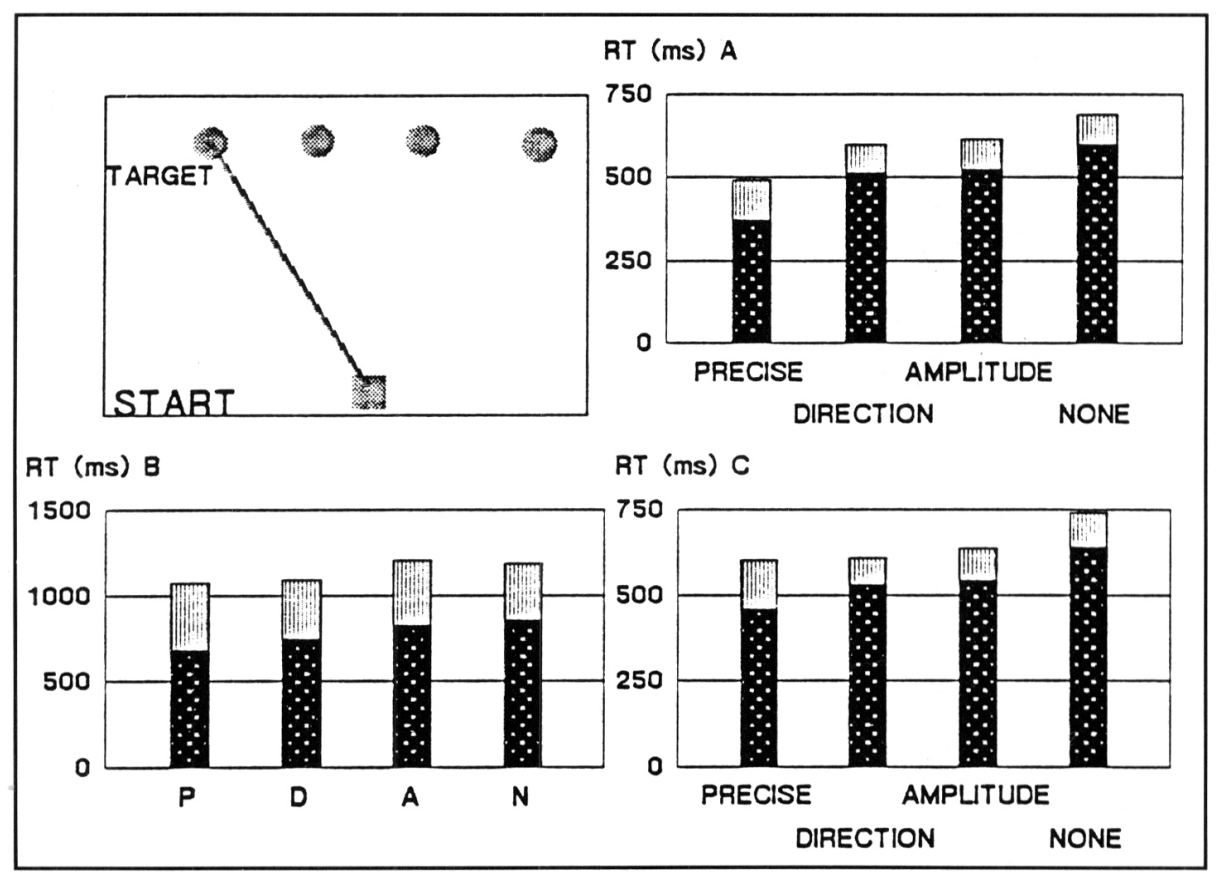

Figure 6 - Influence of the level of precuing information on the reaction time in an arm reaching task. The insert on the left shows the experimental paradigm with the four target areas. Means (grey columns) and standard deviations (black areas) of reaction times are shown for 14 normal subjects $(A), 5$ patients with diffuse cerebellar atrophy $(B)$ and 3 patients with a unilateral cerebellar lesion $(C)$. The reaction time decreases with the level of prior information in normal and patients. Reaction times are prolonged in patients (note the different $y$-scale in B). 


\section{Time Critical Perception}

Timing is an essential feature of repetitive movements like finger tapping or in movements requiring fast changes either in direction of movement or force. In contrast to patients with Parkinson's disease, those with cerebellar lesions show increased variability when attempting to produce periodic intervals in an index finger tapping task. ${ }^{38}$ The analysis of the tapping data was based on a theoretical model of timing developed by Wing and Kristofferson. ${ }^{39}$ This model assumes that the variability of inter-response intervals can be due to variability of a central time keeper system ("clock") and/or a motor implementation system which executes the command. Studies in patients with circumscribed lesions indicated that the cerebellar hemispheres are critically involved in the operation of a central timing process, whereas the medial regions of the cerebellum are associated with the execution of these responses. ${ }^{38}$

More exciting, the timing capabilities of the cerebellum appear to extend beyond movement control. Patients with cerebellar lesions were asked to estimate the duration of the time interval between two pairs of tones. The tones of the first, standard pair were separated by $400 \mathrm{~ms}$, and the tones of the second, test pair created an interval that was either shorter or longer in duration. Perception thresholds were determined in $\mathrm{ms}$ and then converted to standard deviations. In a control experiment, the subjects were required to estimate the difference in loudness of two stimuli. Note that the control experiment is not time-dependent. Cerebellar patients performed normally in the loudness experiment, but were more variable on the duration perception experiment ${ }^{40}$ (Figure 7).

In order to test whether the perceptual problem in cerebellar patients is restricted to the auditory domain, we investigated visual perception of the velocity of moving stimuli. ${ }^{41}$ Velocity perception requires intact perception of time intervals. The subjects were required to judge whether a dotted line moving horizontally at a test velocity was faster or slower than a line moving at a standard velocity. Test velocities ranged from 0.54 to $7.1 \mathrm{deg} / \mathrm{sec}$. Twenty-one patients with cerebellar lesions were tested. This group of subjects was impaired in making the velo- city judgments in comparison to age-matched control subjects (Figure 8). No differences were found between the two groups on a control task in which the vertical position of the test line was varied with respect to a standard position (this task is not time-dependent). The results could not be explained by disturbed eye movements in cerebellar patients because the deficit was also obtained in trials in which fixation was maintained as verified by EOG recordings. ${ }^{41}$ We are currently exploring whether a similar velocity perception deficit is obtained with proprioceptive stimuli. Jointly, these studies provide converging evidence that the cerebellum is important in the computation of time intervals. This timing hypothesis can also account for the role of the cerebellum in locomotion, processes involving efference copy and classical conditioning. ${ }^{42}$

\section{Conclusions}

The present understanding of the physiological mechanisms of ataxia and other cerebellar symptoms in humans is still very preliminary. It must largely resort to the results of animal experiments. The paucity of experimental studies in humans is partly due to the rarity of well-delineated and purely cerebellar lesions in patients. Cerebellar atrophies mostly result in diffuse loss of Purkinje cells and deterioration of afferent and efferent cerebellar pathways. Many patients initially present or develop multi-system-atrophies like OPCA. Vascular lesions frequently involve the brainstem. Tumours may compress neighbouring structures.

Human studies are difficult to compare. The variation of results is due to the population studied (mildly vs severely affected patients), the kind of movement performed (multi-joint vs single joint), the instruction given to the patient (accurate vs fast) and mechanical factors like load and inertia. In addition, the effect of acute cerebellar lesions has not been well-studied in humans. Most of the results in the literature reflect the effects of lesions and the patient's individual strategy for compensation. For example slowness of movement could in part be a learned phenomenon due to patients' awareness that higher movement velocities create a larger amount of hypermetria.
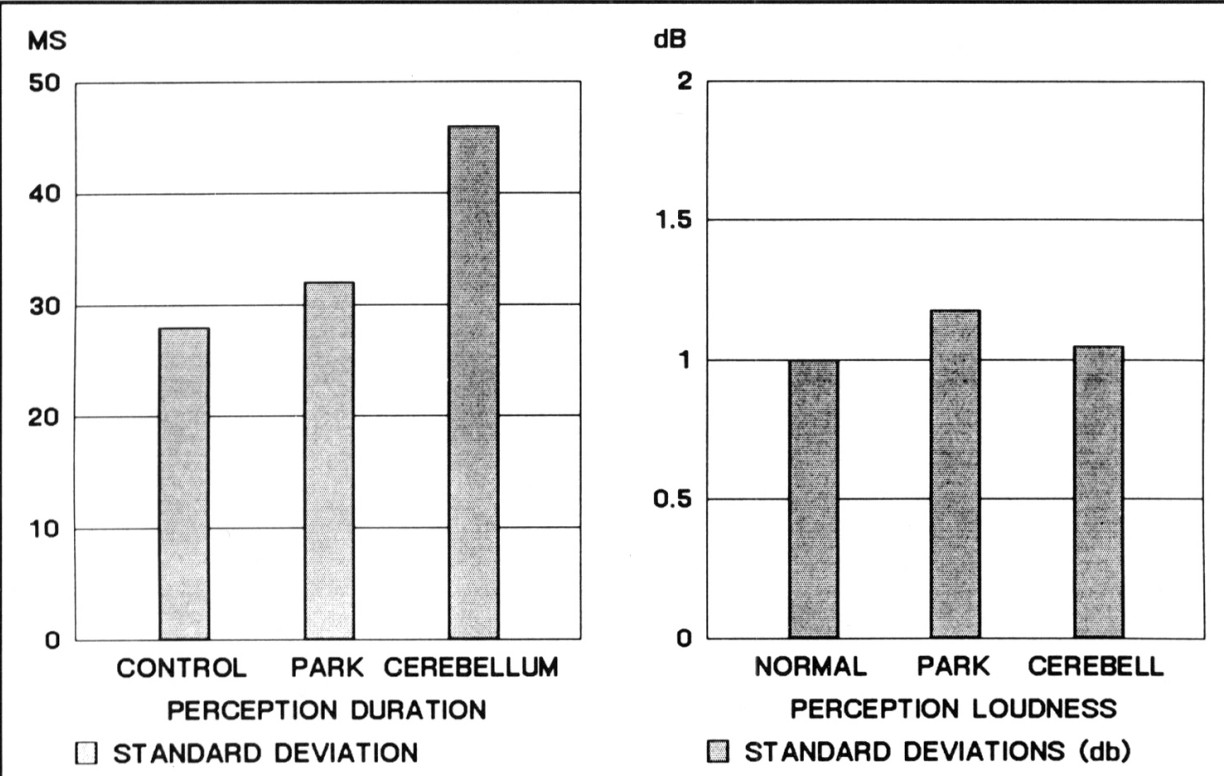

Figure 7 -Perceptual judgments of duration and loudness of two consecutive tones for normal elderly subjects, 23 patients with Parkinson's disease and 30 patients with cerebellar disorders. Results are expressed as mean standard deviation estimates for each group. A perceptual deficit in judgment of duration is exclusively observed in cerebellar patients. Loudness perception is intact $\left(\right.$ from $\left.^{40}\right)$. 


\section{STANDARD DEVIATION}

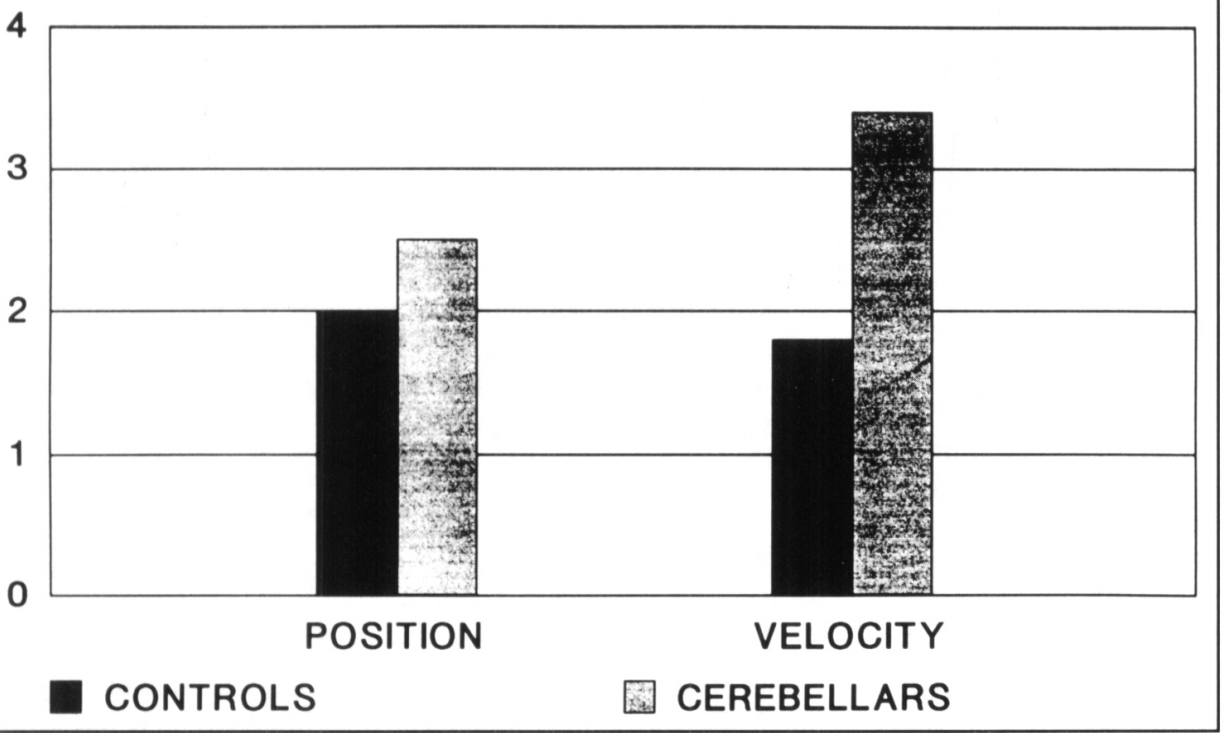

Figure 8-Perceptual judgments of velocity and position of visual stimuli for 16 control subjects and 21 cerebellar patients. Cerebellar patients show impairment in velocity judgments, only. Data are graphed in terms of stimulus step values, equated for the two tasks (based on ${ }^{4 \prime}$ ).

\section{REFERENCES}

1. Holmes G. The symptoms of acute cerebellar injuries due to gunshot injuries. Brain 1917; 40: 461-535.

2. Holmes G. Clinical symptoms of cerebellar disease and their interpretation. The Croonian lectures I. Lancet 1922; 1: 1177-1182.

3. Holmes G. Clinical symptoms of cerebellar disease and their interpretation. The Croonian lectures II. Lancet 1922; 1: 1231-1237.

4. Holmes G. Clinical symptoms of cerebellar disease and their interpretation. The Croonian lectures III. Lancet 1922; 2:59-65.

5. Holmes G. Clinical symptoms of cerebellar disease and their interpretation. The Croonian lectures IV. Lancet 1922; 2: 111-115.

6. Holmes G. The cerebellum of man. Brain 1939; 62: 1-30.

7. Dow RS, Moruzzi G. The Physiology and Pathology of the Cerebellum. Minneapolis: University of Minnesota Press, 1958.

8. Gilman S, Bloedel J, Lechtenberg R. Disorders of the Cerebellum. Philadelphia: Davis, 1981.

9. Brooks VB, Thach WT. Cerebellar control of posture and movement. In: Brookhart JM, Mountcastle VB, eds. Handbook of Physiology, Section 1, Volume 2, Part 2, Bethesda: American Physiological Society, 1981: 877-946.

10. Dichgans J, Diener HC. Clinical evidence for functional compartmentalization of the cerebellum. In: Bloedel JR, Dichgans J, Precht W, eds. Cerebellar Functions. Berlin Heidelberg: Springer 1984; 126-147.

11. Ito M. The Cerebellum and Neural Control. New-York: Raven Press 1984.

12. Marsden CD, Merton PA, Morton HB, et al. Disorders of movement in cerebellar disease in man. In: Rose FC, ed. Physiological Aspects of Clinical Neurology. Oxford: Blackwell 1977; 179199.

13. Meyer-Lohmann J, Hore J, Brooks VB. Cerebellar participation in generation of prompt arm movements. J Neurophysiol 1977; 40: 1038-1050.

14. Lamarre Y, Bioulac B, Jacks B. Activity of precentral neurons in conscious monkeys: effects of deafferentation and cerebellar ablation. J Physiol (Paris) 1978; 74: 253-264.

15. Lamarre $Y$, Jacks $B$. Involvement of the cerebellum in the initiation of fast ballistic movement in the monkey. Electroencephalogr Clin Neurophysiol Suppl 1978; 34: 441-447.

16. Miller AD, Brooks VB. Parallel pathways for movement initiation in monkeys. Exp Brain Res 1982; 45: 328-332.

17. Beaubaton D, Trouche E, Legallet E. Neocerebellum and motor programming: evidence from reaction-time studies in monkeys with dentate nucleus lesions. In: Kornblum S, Requin J, eds.
Preparatory - States \& Processes. Lawrence Erlbaum Ass., Publ. London, Hillsdale New Jersey, 1984: 303-320.

18. Hore J, Wild B, Diener HC. Cerebellar dysmetria at the elbow, wrist and fingers. J Neurophysiol 1991; 65: 563-571.

19. Wild B. Schnelle zielgerichtete Bewegungen der oberen Extremität bei Normalpersonen und cerebellären Patienten. Tübingen: M.D. Thesis, 1990.

20. Beppu H, Suda M, Tanaka R. Analysis of cerebellar motor disorders by visually guided elbow tracking movement. Brain 1984; 107: 787-809.

21. Spidalieri G, Busby L, Lamarre Y. Fast ballistic arm movements triggered by visual, auditory, and somesthetic stimuli in the monkey. II. Effects of unilateral dentate lesion on discharge of precentral cortical neurons and reaction time. J Neurophysiol 1983; 50: 1359-1379.

22. Thach WT. Timing of activity in cerebellar dentate nucleus and cerebral motor cortex during prompt volitional movement. Brain Res 1975; 88: 233-241.

23. Meyer-Lohmann J, Conrad B, Matsunami K, Brooks VB. Effects of dentate cooling on precentral unit activity following torque pulse injections into elbow movements. Brain Res 1975; 94: 237-251.

24. Hore J, Flament D. Changes in motor cortex neural discharge associated with the development of cerebellar limb ataxia. J Neurophysiol 1988; 60: 1285-1302.

25. Hallett M, Berardelli A, Matheson J, Rothwell J, Marsden CD. Physiological analysis of simple rapid movements in patients with cerebellar deficits. J Neurol Neurosurg Psychiatry 1991; 53: 124-133.

26. Flament D, Hore J. Movement and electromyographic disorders associated with cerebellar dysmetria. J Neurophysiol 1986; 55 : 1221-1233.

27. Brown SH, Hefter H, Mertens M, Freund H-J. Disturbances in human arm movement trajectory due to mild cerebellar dysfunction. J Neurol Neurosurg Psychiatry 1990; 53: 306-313.

28. Hallett M, Shahani BT, Young RR. EMG analysis of stereotyped voluntary movements in man. J Neurol Neurosurg Psychiatry 1975; 38: 1154-1162.

29. Becker WJ, Kunesch E, Freund H-J. Coordination of a multi-joint movement in normal humans and in patients with cerebellar dysfunction. Can J Neurol Sci 1990; 17: 264-274.

30. Babinski J. De l'asynergie cérébelleuse. Rev Neurol 1899; 7: 806816.

31. Babinski J. Sur le rôle du cervelet dans les actes volitionnels necessitants une succession rapide de mouvements (diadochocinésie) Rev Neurol 1902; 10: 1013-1015. 
32. Conrad B, Brooks VB. Effects of dentate cooling on rapid alternating arm movements. J Neurophysiol 1974; 37: 792-804.

33. Diener HC, Dichgans J, Guschlbauer B, Bacher M, Rapp H, Klockgether $T$. The coordination of posture and voluntary movement in patients with cerebellar dysfunction. Movement Disorders 1992; 7: 14-22.

34. Keele SW. Movement control in skilled motor performance. Psycholog Bull 1968; 77: 155-158.

35. Inhoff AW, Diener HC, Rafal RD, Ivry R. The role of cerebellar structures in the execution of serial movements. Brain 1989; 112: 565-581.

36. Rosenbaum DA. The movement precuing technique: assumptions, applications, and extensions $\ln$ : Magill RA, ed. Memory and Control of Action. North-Holland Publishing Company, 1983: 23-274.

37. Stelmach GE, Worringham CJ, Strand EA. Movement preparation in Parkinson's disease: the use of advanced information. Brain 1986; 109: 1179-1194.
38. Ivry RB, Keele SW, Diener HC. Dissociation of the lateral and medial cerebellum in movement timing and movement execution. Exp Brain Res 1988; 73: 167-180.

39. Wing A, Kristofferson A. Response delays and the timing of discrete motor responses. Percept Psychophys 1973; 14: 5-12.

40. Ivry RB, Keele SW. Timing functions of the cerebellum. I Cogn Neurosci 1989; 1: 136-152.

41. Ivry RB, Diener HC. Impaired velocity perception in patients with lesions of the cerebellum. J Cogn Neurosci 1991; 3: 355-366.

42. Keele SW, Ivry RB. Does the cerebellum provide a common computation for diverse tasks: a timing hypothesis. $I n$ : Diamond A, ed. Developmental and Neural Basis of Higher Cognitive Function. Ann NY Acad Sci 1991; 179-211. 